УДк 004.9:004.02:658.5: 637.5

\title{
DEVELOPMENT OF THE MODIFIED ITERATION ALGORITHMS TO SOLVE THE PROBLEM OF FORMING THE OPTIMAL VARIANTS OF THE ORDER EXECUTION SCHEDULE
}

\author{
S. Hrybkov, O. Seidykh \\ National University of Food Technologies
}

\begin{tabular}{ll}
\hline \multicolumn{1}{c}{ Key words: } & \multicolumn{1}{c}{ ABSTRACT } \\
mathematical model, &
\end{tabular}

DOI: $10.24263 / 2225-2916-2020-27-16$

(C) С. В. Грибков, О. Л. Сєдих, 2020 


\title{
РОЗРОБКА МОДИФІКОВАНИХ ІТЕРАЦІЙНИХ АЛГОРИТМІВ ДЛЯ РОЗВ'ЯЗАННЯ ЗАДАЧІ ФОРМУВАННЯ ОПТИМАЛЬНИХ ВАРІАНТІВ РОЗКЛАДУ ВИКОНАННЯ ЗАМОВЛЕНЬ
}

\author{
С. В. Грибков, канд. техн. наук \\ О. Л. Седих \\ Національний університет харчових технологій
}

У статті запропоновано математичну модель багатокритеріальної задачі фрормування виробничих завдань та оперативно-календарних планів з виробництва ковбасних і м'ясних виробів. Розроблено удосконалені ітераційні алгоритми на основі алгоритму сірих вовків та алгоритму мурашиної колонії для розв'язання задачі формування оптимальних варіантів розкладу виконання замовлень, що забезпечує при їх застосуванні реконфігурації планів за короткий час.

Ключові слова: математична модель, планування виконання замовлень, алгоритм мурашиної колонії, алгоритм сірих вовків.

Постановка проблеми. Сучасне підприємство харчової промисловості являє собою складній виробничо-господарський комплекс, у розпорядженні якого $\epsilon$ основні виробничі фонди та людські ресурси, необхідні для здійснення виробничих процесів. Насамперед має бути раціонально організований процес виготовлення продукції згідно з потоком замовлень. Основною проблемою для харчових підприємств є невизначеність і швидкі зміни в бізнес-середовищі. Як правило, замовники вимагають виконання своїх замовлень вчасно, в повному обсязі та асортименті.

Складність процесу прийняття рішення про оптимальне виконання замовлень полягає в тому, що необхідно повністю забезпечити потреби замовників, при цьому раціонально використати наявні виробничі потужності та сировинні ресурси, обов'язково забезпечивши виготовлення продукції у задані терміни та в повному обсязі.

Головною особливістю м'ясопереробного виробництва є динаміка різновиду сировини для виготовлення продукції залежно від попиту та обсягу замовлень, що спонукає весь час коригувати виробничі плани, змінні завдання, рецептуру виготовлення без порушень ДСТУ, складність прогнозування виникнення позаштатних ситуацій, визначення коректного технологічного процесу виготовлення продукції та постійне здійснення моніторингу процесу виробництва 3 метою зниження некондиційної продукції.

Важливість і складність задач прийняття рішень на всіх рівнях управління м'ясопереробним виробництвом обумовлює необхідність проведення досліджень, спрямованих на розроблення використання методів, що базуються на нових методах оптимізації з використання інформаційних систем.

Зважаючи на вищевикладене, актуальним завданням є удосконалення методів управління за рахунок створення спеціалізованих методів підтримки прийняття рішення при оперативному плануванні виготовлення продукції.

Останнім часом отримали розвиток метаевристичні алгоритми, які дають змогу за короткий час вирішувати більшість задач управління складними ієрархічними системами та технологічними комплексами. Але існуючі метаевристичні алгоритми 
доцільно модифікувати та адаптувати до задач, пов'язаних з оперативним плануванням виготовлення продукції.

Аналіз останніх досліджень і публікацій. У [1] запропоновано інформаційну технологію для розв' язання задачі планування виконання замовлень з виготовленню продукції на харчових підприємствах, яка грунтується на комбінуванні алгоритмів мурашиної колонії, сірих вовків і генетичного. Але використані методи висвітлені недостатньо.

У [2] авторами запропоновано математичну модель задачі планування виконання договорів і метод мурашиної колонії для ії розв'язання. Але недоліком запропонованого підходу є орієнтованість на підприємства з надання послуг, що не дає змогу врахувати обмеження на обсяги необхідної для виготовлення харчової продукції сировини та пакувальних матеріалів, терміни зберігання готової продукції.

У [3] розглянуто алгоритм планування на основі алгоритму штучної бджолиної колонії з методом локального пошуку, який базується на основі жадібної конструктивно-деструктивної процедури. Наведений алгоритм не дає змоги враховувати пріоритети часткових критеріїв та обмежень.

У дослідженні [4] наведена математична модель, яка враховує лише деякі критерії ефективності при плануванні виконання операцій на різних технологічних машинах. Але розглянутий метод гілок і границь має складності при вирішенні задач для обладнання, яке використовується паралельно.

У [5] запропоновано структуру нечіткої ситуаційної мережі для системи підтримки прийняття рішень, яку використовують для розв'язання слабкоструктурованих або неструктурованих проблем, а також для опису проблемних ситуацій при відсутності точних моделей. Запропонований підхід [5] забезпечує підвищення якості управління організаційно-технічними (технологічними) системами.

Авторами [6] здійснено дослідження теоретичних підходів планування виробничих процесів, а також виділено чинники, що негативно впливають на процес планування з використанням методів оптимізації.

Метою дослідження $є$ підвищення ефективності управління виробничим процесом на підприємстві виготовлення ковбасних і м'ясних виробів технологом підприємства за рахунок розробки модифікованих ітераційних алгоритмів для розв'язання задачі формування оптимальних варіантів розкладу виконання замовлень.

Для вирішення поставленої мети вирішено такі завдання:

- формалізація та математичне моделювання виконання замовлень на виготовлення ковбасної та м’ясної продукції, що враховує всі критерії впливу на отримання кінцевого прибутку;

- створення та модифікації метаеврестичних алгоритмів розв'язання задачі формування оптимальних варіантів розкладу виконання замовлень.

Методи і матеріали. Під час дослідження використано методи теоретичного узагальнення, наукової індукції та дедукції, математичного та структурного аналізів, праці зарубіжних і вітчизняних вчених.

Результати досліджень. Загальна оціночна функція, що визначатиме ефективність варіанту плану для м'ясопереробного підприємства на заданий період, представлена адитивною згорткою часткових критеріїв (1):

$$
F_{0}^{\prime}=\lambda_{1} F_{1}-\sum_{\gamma=3}^{7} \lambda_{\gamma} F_{\gamma} \rightarrow \max ,
$$

де $\lambda_{\gamma}$ - коефіцієнт важливості кожного критерію $\lambda_{\gamma} \epsilon$ [1]. 
Кожен частковий критерій [7] розглянемо детально.

Першим критерієм $є$ максимальний прибуток, отриманий при виконанні всіх замовлень за плановий період $(t+\Delta t)(1)$ :

$$
\begin{aligned}
& F_{1}(t+\Delta t)= \\
& =\sum_{i=1}^{n}\left(\theta_{i} *\left(s d_{i}(t+\Delta t)-\left(v c_{i}(t+\Delta t)+v z_{i}(t+\Delta t)\right)\right)\right) * o p_{i}(t+\Delta t) \rightarrow \max
\end{aligned}
$$

де $t$ - час початку виконання плану, який позначається датою та часом до хвилини;

$\Delta t$ - час, за який необхідно виконати всі замовлення в хвилинах;

$(t+\Delta t)$ - плановий період на який розраховується виробничий план;

$i$ - замовлення, що знаходиться на черзі, регламентує один вид продукції, яку необхідно виготовити за період $(t+\Delta t)$;

$n-$ загальна кількість замовлень, які необхідно виконати за період $(t+\Delta t)$;

$\theta_{i}$ - параметр, що приймає значення $\{0,1\}\left(\theta_{i}=1\right.$, якщо $i$-е замовлення виконується за період $(t+\Delta t) ; \theta_{i}=0$ в іншому випадку);

$s d_{i}(t+\Delta t)$ - вартість одиниці продукції для $i$-о замовлення за період $(t+\Delta t)$;

$v c_{i}(t+\Delta t)$ - постійні витрати на виготовлення одиниці продукції для $i$-го замовлення за період $(t+\Delta t)$;

$v z_{i}(t+\Delta t)$ - зміні витрати на виготовлення одиниці продукції для $i$-го замовлення за період $(t+\Delta t)$;

$o p_{i}(t+\Delta t)-$ обсяг готової продукції, яку необхідно виготовити за $i$-м замовленням у період $(t+\Delta t)$.

Другим критерієм $\epsilon$ мінімізація часу на виготовлення продукції кожного $i$-го замовлення за період $(t+\Delta t)(3)$, а також обмеження (4) та (5), що регламентують час виготовлення кожної продукції для $i$-го замовлення та обмеження на термін закінчення виготовлення продукції, що повинно не перевищувати визначеного терміну:

$$
\begin{gathered}
F_{2}(t+\Delta t)=\max _{i}\left(F_{2 i}(t+\Delta t)\right)= \\
=\max _{i}\left(\sum_{j=1}^{\omega_{i}} \sum_{l=1}^{\sigma_{i}}\left(o_{i j l} *\left(p t_{i j l}+t_{i j l}+\eta t_{i j l}+t o_{i j-1}\right)\right)\right) \rightarrow \min ; \\
t \leq t_{i}+F_{2 i}(t+\Delta t) \leq t+\Delta t ; \\
t \leq t_{i}-F_{2 i}(t+\Delta t) \leq d t_{i},
\end{gathered}
$$

де $(t+\Delta t)$ - плановий період на який розраховується виробничий план;

$i$ - замовлення, що знаходиться на черзі, регламентує один вид продукції, яку необхідно виготовити за період $(t+\Delta t)$;

$j$ - номер етапу з множини етапів $\left(j \epsilon \omega_{i}\right)$ для $i$-о замовлення, де $\omega_{i}-$ кількість необхідних етапів виготовлення $i$-го замовлення;

$l$ - номер обладнання 3 множини обладнання $\left(j \epsilon \sigma_{i}\right)$ для $i$-го замовлення, де $\sigma_{i}-$ кількість задіяного обладнання для виконання усіх етапів при виготовленні $i$-го замовлення;

$t_{i}$ - час початку виконання виготовлення продукції за $i$-м замовленням;

$p t_{i j l}$ - час, необхідний для підготовки $l$-го обладнання для здійснення $j$-о етапу при виготовленні продукції за $i$-м замовленням, може приймати нуль, якщо підготовка не потрібна; 
$\eta t_{i j l}$ - час для очищення обладнання після $j$-го етапу виготовлення продукції за $i$-м замовленням на $l-y$ обладнанні, якщо воно не буде використовуватися найближчим часом;

$o_{i j l}$ - параметр, що приймає значення $\{0,1\}$ ( $o_{i j l}=1$, якщо $j$-й етап можливо виконати на $l-y$ обладнанні для виготовлення продукції за $i$-м замовленням; $o_{i j l}=0$ в іншому випадку);

$n-$ загальна кількість замовлень, які необхідно виконати за період $(t+\Delta t)$;

$\omega_{i}$ - кількість технологічних етапів для виконання $i$-го замовлення;

$\sigma_{i}$-кількість задіяного обладнання для виконання усіх етапів при виготовленні $i$-го замовлення;

$t_{i j-1}$ — час переходу/очікування між виконанням $j$-го етапу до $(j-1)$ етапу;

$d t_{i}$ - час, за який необхідно виготовити продукцію за $i$-м замовленням.

Третім критерієм $\epsilon$ мінімізація сумарних штрафів за невчасне виконання замовлення за період $(t+\Delta t)(6)$ :

$$
F_{3}(t+\Delta t)=\sum_{i=1}^{n}\left(g_{i} * \psi_{i} * h k_{i}\right) \rightarrow \min ,
$$

де $(t+\Delta t)-$ плановий період на який розраховується виробничий план;

$i$ - замовлення, що знаходиться на черзі, регламентує один вид продукції, яку необхідно виготовити за період $(t+\Delta t)$;

$n$ - загальна кількість замовлень, які необхідно виконати за період $(t+\Delta t)$;

$g_{i}$ - розмір штрафу прописаний у договорі, який необхідно відшкодувати замовнику, якщо буде порушено $d t_{i}$ термін виконання замовлення;

$\Psi_{i}$ - коефіцієнт, що приймає значення $\{0,1\}, \Psi_{i}=1$ якщо $\left(t_{i}+F_{2 i}(t+\Delta t)\right)<d t_{i}, \Psi_{i}=0$ в іншому випадку, та визначає необхідність відшкодування замовнику, якщо буде порушено термін виконання $d t_{i}$;

$h k_{i}$ - коефіцієнт, який враховує необхідність сплати штрафу за запізнення на кожну добу.

Четвертим частковим критерієм є мінімізація сумарних витрат при проходженні усього технологічного процесу через відповідні технологічні ділянки при виконанні замовлень за заданий період $(t+\Delta t)(7)$ :

$$
F_{4}(t+\Delta t)=\sum_{i=1}^{n}\left(\sum_{j=1}^{\omega_{i}} \sum_{l=1}^{\sigma_{i}}\left(\left(o_{i j l} *\left(p t_{i j l}+t_{i j l}+\eta t_{i j l}\right)\right) * c_{i j l}\right)\right) \rightarrow \min ,
$$

де $(t+\Delta t)-$ плановий період на який розраховується виробничий план;

$i$ - замовлення, що знаходиться на черзі, регламентує один вид продукції, яку необхідно виготовити за період $(t+\Delta t)$;

$j$ - номер етапу з множини етапів $\left(j \in \omega_{i}\right)$ для $i$-го замовлення, де $\omega_{i}-$ кількість необхідних етапів виготовлення $i$-го замовлення;

$l$ - номер обладнання $з$ множини обладнання $\left(j \in \sigma_{i}\right)$ для $i$-го замовлення, де $\sigma_{i}$ - кількість задіяного обладнання для виконання усіх етапів при виготовленні $i$-го замовлення;

$p t_{i j l}$ - час необхідний для підготовки $l$-го обладнання для здійснення $j$-го етапу при виготовленні продукції за $i$-м замовленням, може приймати нуль, якщо підготовка не потрібна;

$\eta t_{i j l}$ - час для очищення обладнання після $j$-о етапу виготовлення продукції за $i$-м замовленням на $l$-му обладнанні, якщо воно не потрібно або це необхідно перед проведення ремонтно-профілактичних робіт; 
$o_{i j l}$ - параметр, що приймає значення $\{0,1\}$ (oijl $=1$, якщо $j$-й етап можливо виконати на $l$-мy обладнанні для виготовлення продукції за $i$-м замовленням; $o_{i j l}=0$ в іншому випадку);

$n$ - загальна кількість замовлень, які необхідно виконати за період $(t+\Delta t)$;

$\omega_{i}$ - кількість технологічних етапів для виконання $i$-го замовлення;

$\sigma_{i}$ - кількість задіяного обладнання для виконання всіх етапів при виготовленні $i$-го замовлення;

$c_{i j l}$ — витрати за одну годину при здійсненні $j$-го етапу на $l$-мy обладнанні для виготовлення продукції за $i$-м замовленням.

П'ятим частковим критерієм є мінімізація витрат на переробку та утилізацію отриманої некондиційної продукції при виконанні усіх замовлень (8):

$$
F_{5}(t+\Delta t)=\sum_{i=1}^{n} \sum_{j=1}^{\omega_{i}} \sum_{l=1}^{\sigma_{i}}\left(o_{i j l} * c n_{i j l} * v n k_{i j l} * o p(t+\Delta t)\right) \rightarrow \min
$$

де $(t+\Delta t)-$ плановий період на який розраховується виробничий план;

$i$ - замовлення, що знаходиться на черзі, регламентує один вид продукції, яку необхідно виготовити за період $(t+\Delta t)$;

$j$ - номер етапу з множини етапів $\left(j \epsilon \omega_{i}\right)$ для $i$-го замовлення, де $\omega_{i}-$ кількість необхідних етапів виготовлення $i$-го замовлення;

$l$ - номер обладнання 3 множини обладнання $\left(j \in \sigma_{i}\right)$ для $i$-го замовлення, де $\sigma_{i}$ - кількість задіяного обладнання для виконання усіх етапів при виготовленні $i$-го замовлення;

$n$ - загальна кількість замовлень, які необхідно виконати за період $(t+\Delta t)$;

$\omega_{i}-$ кількість технологічних етапів для виконання $i$-го замовлення;

$\sigma_{i}$ - кількість задіяного обладнання для виконання всіх етапів при виготовленні $i$-го замовлення;

$o_{i j l}$ - параметр, що приймає значення $\{0,1\}$ ( $o_{i j l}=1$, якщо $j$-й етап можливо виконати на $l$-мy обладнанні для виготовлення продукції за $i$-м замовленням; $o_{i j l}=0$ в іншому випадку);

$o_{i}(t+\Delta t)-$ обсяг готової продукції, яку необхідно виготовити за $i$-м замовленням у період $(t+\Delta t)$;

$c n_{i j l}$ — вартість перероблення чи утилізації одиниці отриманої некондиційної продукції при виконанні $i$-го замовлення на $l$-му технологічному обладнанні;

$v n k_{i j l}$ - загальна кількість некондиційної продукції, отриманої на кожну одиницю продукції під час виконання $j$-го етапу $i$-го замовлення на $l$-му технологічному обладнанні.

Шостим критерієм є мінімізація витрат на зберігання готової продукції до заданого терміну відвантаження (9):

$$
F_{6}(t+\Delta t)=\sum_{i=1}^{n}\left(v z_{i} * o p(t+\Delta t) * \max \left(0, d t_{i}-\left(t_{i}+F_{2 i}(t+\Delta t)\right)\right) \rightarrow \min ,\right.
$$

де $(t+\Delta t)-$ плановий період на який розраховується виробничий план;

$i$ - замовлення, що знаходиться на черзі, регламентує один вид продукції, яку необхідно виготовити за період $(t+\Delta t)$;

$t_{i}$ - час початку виконання виготовлення продукції за $i$-м замовленням;

$n$ - загальна кількість замовлень, які необхідно виконати за період $(t+\Delta t)$;

$v z_{i}(t+\Delta t)$ - зміні витрати на виготовлення одиниці продукції для $i$-го замовлення за період $(t+\Delta t)$;

$o p_{i}(t+\Delta t)-$ обсяг готової продукції, яку необхідно виготовити за $i$-м замовленням у період $(t+\Delta t)$; 
$d t_{i}$ - час, за який необхідно виготовити продукцію за $i$-м замовленням.

Сьомим критерієм є мінімізація витрат на зберігання сировини та матеріалів, що необхідні для виготовлення продукції (10):

$$
F_{7}(t+\Delta t)=\sum_{i=1}^{n} \sum_{k=1}^{r_{i}}\left(v s r_{i k} * r k_{i k} * o p(t+\Delta t) * \max \left(0, t_{i}-r t_{i k}\right) \rightarrow \min ,\right.
$$

де $(t+\Delta t)-$ плановий період на який розраховується виробничий план;

$i$ - замовлення, що знаходиться на черзі, регламентує один вид продукції, яку необхідно виготовити за період $(t+\Delta t)$;

$k$ - вид сировини (матеріалу) необхідного для виконання $i$-го замовлення, а загальна його кількість необхідних для виконання $i$-го замовлення $r_{i}$;

$n$ - загальна кількість замовлень, які необхідно виконати за період $(t+\Delta t)$;

$r_{i}$ — перелік ресурсів, необхідних для виготовлення продукції за і-м замовленням;

$t_{i}$ - час початку виконання виготовлення продукції за $i$-м замовленням;

$o p_{i}(t+\Delta t)-$ обсяг готової продукції, яку необхідно виготовити за $i$-м замовленням у період $(t+\Delta t)$;

$r k_{i k}$ - обсяг сировини, необхідний для виготовлення одиниці продукції за $i$-м замовленням;

$r t_{i k}$ - час надходження $k$-го компонента для виконання $i$-го замовлення;

$v s r_{i k}$ - вартість зберігання $k$-го компонента для виконання $i$-го замовлення.

Математична модель $\epsilon$ комбінаторною багатокритеріальною NP-повною задачею. Вона включає цілу низку обмежень: загальний обсяг виготовлення продукції не повинен бути більшим, ніж потужність підприємства на заданий період; не можливо порушувати вимоги й терміни зберігання сировини та матеріалів; не можливо порушувати вимоги й терміни зберігання готової продукції; на певний проміжок часу дозволено використовувати кожне технологічне обладнання для виготовлення тільки одного виду продукції чи напівфабрикату, адже не можливо використовувати технологічне обладнання для виготовлення водночас різних видів продукції за різними рецептурами та компонентним складом.

Крім того,розроблено два нових модифікованих методи зграї сірих вовків та мурашиної колонії, а також проведено їх порівняння.

Алгоритм зграї вовків заснований на їхньому полюванні в природі [8]. Відповідно до нашої задачі, зграя полює за жертвою, яка відповідає оптимальному оперативному плану виконання замовлень. Кожен вовк зграї відповідає альтернативному оперативному плану $L_{i t}$, де $i$-те замовлення на ітерації $\imath$ [9]. Після виконання кожної ітерації для кожного вовка розраховується значення його альтернативного оперативного плану, використовуючи часткові критерії або оціночну функцію $F_{0}$ '. За значенням оцінки кожного вовка у зграї виділяють чотири типи вовків: «альфа» - ватажок зграї, оцінка якого має найоптимальніше рішення; «бета» та «дельта» - це вовки, які займають друге та третє місце серед найкращих і дуже наближені до оптимального поточного рішення; «омега» — всі інші. Перші три типи вовків фіксуються на наступній ітерації до тих пір, поки не буде знайдено нові альтернативні варіанти рішення, що будуть кращі за поточні, або буде вичерпано задану кількість ітерацій.

При закінченні кожної ітерації $\imath$ проводимо аналіз «альфа», «бета», «дельта» вовків та виділяємо шаблон $W_{s}$ - однакові позиції з однаковими значеннями в усіх трьох варіантах. $W_{s}$ буде використаний для формування «омега вовків» на наступній ітерації. Усі інші потрапляють у шаблон $W_{z}$. Шаблон $W_{s}$ та $W_{z}$ представляються як 
одновимірні вектори, перелік індексів елементів, що не будуть змінюватися, позначаємо $J_{w s}$, а перелік індексів елементів, що будуть змінюватися, позначаємо $J_{w z}$.

Необхідно відмітити, що зміни «омега» вовків відбуваються за правилом: усі вовки мають однакову швидкість, що дає змогу на кожній ітерації поміняти місцями тільки два замовлення у послідовності виконання з шаблону $W_{z}$.

Вовки, що повністю збігаються із шаблоном, модифікуються за правилом, яке описане формулою (11):

$$
\begin{aligned}
& v=W_{z}(j+r * a), \\
& W_{z}(j+r * a)=W_{z}(j), \\
& W_{z}(j)=v
\end{aligned}
$$

де $j$ - індекс елемента, значення якого буде замінено на значення елемента 3 індексом $j+r^{*} a$, а його значення генерується випадково $j=r n d\left(J_{w z}\right) 3$ елементів множини $J_{w z}\left(j \epsilon J_{w z}, j+r^{*} a \epsilon J_{w z}, 0<j \leq J_{w z}, 0<j+r^{*} a \leq n\right.$, де $n-$ кількість замовлень);

$r$ - коефіцієнт, що визначає напрямок руху вовка і визначається 3 використанням генератора випадкових чисел $r=r n d(-1 ; 1)$;

$a$ - коефіцієнт розміру кроку вовка, визначається з використанням генератора випадкових чисел $a=r n d(1 ; 2)$.

Вовки, що тільки частково збігаються із шаблоном, змінюються за наступним алгоритмом:відбувається порівняння поточного $W_{i}$ із шаблоном $W s$ та відшукується $j_{a i}$ - індекс елемента в поточному, що не збігається за значенням 3 елементом в шаблоні $W_{i}\left(j_{a i}\right) \neq W_{s}\left(j_{a i}\right)$; знаходимо $j_{a i}$ - індекс елемента у $W_{i}$, що дорівнює значенню $W_{s}\left(j_{a i}\right)$, тобто $W_{i}\left(j_{a i}\right)=W_{s}\left(j_{a i}\right)$ при цьому $j_{a i} \neq j_{a i}$; здійснюємо заміну $W_{i}\left(j_{b i}\right)=W_{i}\left(j_{a i}\right)$, а потім $W_{i}\left(j_{a i}\right)=W_{i}\left(j_{a i}\right)$.

Авторами пропонується здійснювати розширення популяції вовків на кожній 3 та 5 ітерації алгоритму при формуванні всіх нових вовків за правилом (19). При цьому необхідно відслідковувати загальну кількість вовків популяції, яка не повинна перевищувати $2 n$.

В основі алгоритму мурашиної колонії покладено принцип колективного розуму, на прикладі їх поведінки при знаходженні оптимальних маршрутів для пошуку їжі $[1 ; 10]$ за рахунок того, що відбувається багаторазовий ітераційний пошук найкращої послідовності виконання замовлень одночасно заданою кількістю популяції мурах. При цьому кожна мураха відповідає одному з варіантів розкладу виконання замовлень.

Імовірність переходу $i$-ї мурахи у вершину $b$ з вершини $a$ на $l$-й ітерації визначається за формулою (12):

$$
P_{a, b}(l, i)=\left\{\begin{array}{l}
\frac{\left[\xi_{a, b}(l, i)\right]^{\alpha} *\left[\eta_{a, b}(l)\right]^{\beta}}{\sum_{\ell \in L n_{a, i}}\left[\xi_{a, \ell}(l, i)\right]^{\alpha} *\left[\eta_{a, \ell}(l)\right]^{\beta}}, \text { якщо } b \in L n_{a, i}, \\
0, \text { якщо } b \notin L n_{a, i}
\end{array}\right.
$$

де $\alpha$ - коефіцієнт ваги феромону, $0 \leq \alpha \leq 1$, який визначає відносну значимість впливу інтенсивності відміток на вибір шляху, при $\alpha=0$ буде обрано найкоротше ребро, при $\alpha=1$ буде обрано найдовше;

$\beta$ - коефіцієнт видимості при виборі маршруту, $0 \leq \beta \leq 1$, яка визначає відносну значимість впливу видимості на вибір шляху;

$\alpha+\beta=1$, при цьому коефіцієнт $\alpha$ визначає жадібність алгоритму, а $\beta$ - стадність. 
Після завершення маршруту кожна мураха відкладає на кожному ребрі-кількість феромонів, що включені до іiі маршруту, та відповідає розкладу, що розраховуються за формулою (13):

$$
\Delta \xi_{a, b}(l, i)=\left\{\begin{array}{l}
\frac{1}{F_{0}^{\prime}} * \frac{Q}{S_{i}(l)}, \text { якщо }(a, b) \in L t_{i}(l) \\
0, \text { якщо }(a, b) \notin L t_{i}(l)
\end{array},\right.
$$

де $a$ та $b$ - індекси пари вузлів, що поєднують ребро яким пройшов агент;

$L t_{i}(l)$ - сформований маршрут на $l$-й ітерації $i$-ю комахою;

$S_{i}(l)$ - довжина маршруту $L t_{i}(l)$, яка виражена у часі або у вартості;

$Q$ - регульований параметр, що наближений до оптимального маршруту, що заданий чи розрахований за попередні ітерації;

$F_{0}{ }^{\prime}$ - оцінка маршруту згідно з обраним частковим критерієм або оціночною функцією.

Для того, щоб кількість відкладених феромонів не було надлишковою проводиться їх оновлення за формулою (14):

$$
\xi_{a, b}(l+1)=(1-\rho) * \xi_{a, b}(l)+\sum_{i=1}^{n} \Delta \xi_{a, b}(l, i),
$$

де $n$ - кількість мурах, що відповідає кількості замовлень;

$\rho \epsilon[0,1]$ - коефіцієнт випаровування феромону.

Для захисту від передчасного знаходження субоптимального рішення пропонується введення обмежень на концентрацію феромонів на ребрах ( $\left.\xi_{\min } \leq \xi_{\mathrm{a}, \mathrm{b}} \leq \xi_{\max }\right)$. (15):

Оновлення кількості феромонів на ребрах графа буде визначатися за формулою

$$
\xi_{a, b}(l+1)=(1-\rho) * \xi_{u, r}(l)+\Delta \xi_{a, b, b e s t}=(1-\rho) * \xi_{a, b}(l)+\frac{1}{L t_{\text {best }}(l)},
$$

де $L t_{\text {best }}(l)$ - найкращій сформований маршрут на $\imath$-й ітерації.

Після кожної ітерації алгоритму залишає за собою слід лише одна мураха на вибір з двох варіантів: краща на поточній ітерації $L t_{\text {best }}(l)=L t_{l}$ best $(l)$; краща за весь час роботи алгоритму $L t_{\text {best }}(l)=L t_{g l}$ best $(l)$.

При цьому на кожній ітерації виконується коригування кількості феромону на кожному ребрі графа за формулою (16):

$$
\xi_{a, b}(l)=\left\{\begin{array}{l}
\xi_{\min }, \text { якщо } \xi_{a, b}(l)<\xi_{\min }, \\
\xi_{a, b}, \text { якщо } \xi_{\min }<\xi_{a, b}(l) \leq \xi_{\max }, \\
\xi_{\max }, \text { якщо } \xi_{\max }<\xi_{a, b}(l)
\end{array}\right.
$$

Використання операцій диверсифікації здійснюється, якщо за час від останньої ініціалізації не сталося покращання глобального рішення на кожні $l_{\max } / 5$ або $l_{\max } / 10$ ітерації.

Визначення максимального значення феромонів відбувається за формулою (18):

$$
\xi_{\text {max }}=\frac{1}{\rho^{*} L t_{\text {gl_best }}(\imath)},
$$

де $L t_{g l b e s t}(l)$ - краща мураха за весь час роботи алгоритму.

Мінімальне значення концентрації феромону на ребрі обчислюється за формулою (19): 


$$
\xi_{\min }=\frac{\xi_{\max }}{2 * n}
$$

де $n$ - кількість мурах, що відповідає кількості замовлень.

Отже, після врахування всіх модифікацій алгоритм розв'язку матиме такий вигляд [10]:

1. Обрання періоду планування - згідно із заданим періодом обираються замовлення, що необхідно виконати за цей період на певному обладнанні.

2. Обрання оціночної функції та часткових критеріїв вибору для розв'язання задачі.

3. Формування багатошарового графу.

4. Ініціалізація параметрів алгоритму, обрання правил розрахунку розрахункових параметрів; сортуємо за параметром $d t_{i}$ усі замовленням.

5. Будуємо початкові маршрути та формуємо популяцію мурах з використанням генератора випадкових чисел.

6. Виконуємо цикл за часом життя колонії $\imath_{\max } \epsilon 1 . . l$.

7.1. Виконуємо цикл по всіх мурахах $i \epsilon 1 . . n$ (будується маршрут для кожної нової мурахи за (12) і розраховується довжина $\operatorname{Lt}_{l}(l)$; застосовуємо до маршруту локальний пошук; проводимо виділення феромонів за формулою (15)).

7.2. Проводимо оцінку кожного з маршрутів та порівнюємо їх 3 локальним й глобальним оптимальним значенням.

7.3. Виконуємо оновлення феромону на всіх ребрах графа (14).

8. Визначення найкращого локального та глобального оптимуму.

Після отримання результату ОПР визначає, чи приймати запропонований варіант виконання замовлень, чи почати новий пошук. Апробація модифікованих алгоритмів і порівняння їх 3 іншими проводились на основі статистичних даних ТОВ «Слобожанський бекон».

У табл. 1 наведено ряд показників, що відображають ефективність кожного методу при плануванні виконання 150 замовлень.

Таблиия 1. Порівняння застосування алгоритмів

\begin{tabular}{|c|c|c|c|c|c|}
\hline $\begin{array}{l}\text { № } \\
\Pi / \Pi\end{array}$ & Назва алгоритму & $\begin{array}{c}\text { Час пошуку } \\
\text { оптимального } \\
\text { плану, хв }\end{array}$ & $\begin{array}{c}\text { Кількість } \\
\text { ітерацій, } \\
\text { здійснених } \\
\text { для пошуку }\end{array}$ & $\begin{array}{c}\text { Ефективність } \\
\text { знайденого } \\
\text { плану, у.о }\end{array}$ & $\begin{array}{c}\text { Скорочення } \\
\text { часу } \\
\text { виконання } \\
\text { замовлень, } \\
\text { год } \\
\end{array}$ \\
\hline 1. & $\begin{array}{c}\text { Класичний генетичний } \\
\text { алгоритм }\end{array}$ & 47 & 4371 & 3217 & 50 \\
\hline 2. & $\begin{array}{c}\text { Класичний алгоритм } \\
\text { зграї вовків }\end{array}$ & 35 & 3129 & 3217 & 50 \\
\hline 3. & $\begin{array}{c}\text { Модифікований } \\
\text { алгоритм зграї вовків }\end{array}$ & 22 & 2372 & 3679 & 32 \\
\hline 4. & $\begin{array}{l}\text { Класичний алгоритм } \\
\text { мурашиної колонії }\end{array}$ & 34 & 3879 & 3126 & 50 \\
\hline 5. & $\begin{array}{c}\text { Модифікований } \\
\text { алгоритм мурашиної } \\
\text { колонії } \\
\end{array}$ & 28 & 2456 & 3679 & 32 \\
\hline
\end{tabular}

Аналіз проведених результатів надає можливість стверджувати, що алгоритми «Модифікований алгоритм мурашиної колонії» та «Модифікований алгоритм зграї 
вовків» знайшли однакові ефективні рішення. Але вони відрізняються за часом виконання. Інші алгоритми знайшли також ефективні альтернативні рішення, але було витрачено більше часу, що свідчить про те, що задача має різні альтернативні рішення. Бажано використовувати для задач з великою розмірністю «Модифікований алгоритм мурашиної колонії» та «Модифікований алгоритм зграї вовків», а потім порівнювати результат.

Для більшої ефективності доцільно поєднувати декілька алгоритмів для розв’язку однієї задачі, що дає змогу скоротити час виконання кожного окремого алгоритму і не дасть при розв'язку задачі потрапити у локальний оптимум.

Висновки. За результатами проведених досліджень:

- розроблена математична модель планування виконання замовлень 3 урахуванням основних особливостей діяльності підприємств з виробництва ковбасних і м'ясних виробів, що дає змогу оцінити формування оптимальних варіантів розкладу виконання замовлень;

- створені суттєво нові модифіковані алгоритм мурашиної колонії та алгоритм сірих вовків, що забезпечують формування альтернативних планів виконання замовлень з урахування запропонованої математичної моделі, застосування яких дає змогу формувати нові та проводити реконфігурації існуючих планів за короткий час.

\section{ЛІТЕРАТУРА}

1. Грибков C. B. Web-оріснтована система підтримки прийняття рішень при плануванні виконання договорів / С. В. Грибков, Г. В. Олійник, В. А. Литвинов // Східно-європейській журнал передових технологій, V 3, № 2(93):2018. C. 13-24. DOI: https://doi.org/10.15587/17294061.2018.132604.

2. Грибков С. В. Розробка інформаційної технології планування виконання замовлень для харчового підприємства / С. В. Грибков, О. В. Харкянен, В. О. Овчарук, І. В. Овчарук // Східноєвропейській журнал передових технологій, V 1, № 3(103):2020. С. 62-73. DOI: https://doi. org/10.15587/1729-4061.2020.195455.

3. Rodriguez F. J. An artificial bee colony algorithm for the maximally diverse grouping problem / F. J. Rodriguez, M. C. Lozano, C. I. García-Martínez, J. D. González-Barrera // Information Sciences, 230. 2013. P. 183-196. DOI: https://doi.org/10.1016/j.ins.2012.12.020.

4. Yang-Kuei Lin Scheduling efficiency on correlated parallel machine scheduling problems // Operational Research. 2018. Vol. 18. Issue 3. P. 603-624. DOI:https://doi.org/10.1007/s12351-0170355-0.

5. Бойко Р. О. Мережеві структури при керуванні складними організаційно-технічними (технологічними) системами / Р. О. Бойко, С. В. Грибков // Харчова промисловість. 2019. № 25. C. 116-123. Режим доступу: http://nbuv.gov.ua/UJRN/Khp_2019_25_17.

6. Georgiadis G. P., Elekidis A. P., Georgiadis M. C. Optimization-Based Scheduling for the Process Industries: From Theory to Real-Life Industrial Applications. Processes. 2019. 7. 438. P. 135. doi: https://doi.org/10.3390/pr7070438.

7. Грибков С. В. Математичне моделювання оперативного планування виготовлення продукції на ТОВ «Слобожанський бекон» / С. В. Грибков, О. О. Фурта // Наукові праці Другої міжнар. наук.-практ. конф. «Сучасні тенденції розвитку інформаційних систем і телекомунікаційних технологій»— К.: НУХТ, 2019. С. 332.

8. Лагунова А. Алгоритм стаи серых волков для задач оптимизации / А. Д. Лагунова // Научно-практический электронный журнал Оригинальные исследования (ОРИС). — 2019. C. $52-62$.

9. Сагун А. В. Метод стаи волков и его модификация для решения задачи поиска оптимального пути / А. В. Сагун, В. В. Хайдуров, В. І. Кунченко-Харченко // Науковий журнал Фізико-математична освіта. - 2017. - С. 135-139.

10. Желдак Т. Застосування методу моделювання колонії мурах до розв'язання комбінаторних задач планування виконання замовлень металургійними підприємствами / Т. А. Желдак // ISSN 1028-9763. Математичні машини і системи. — 2013. — С. 95-106. 


\title{
РАЗРАБОТКА МОДИФИЦИРОВАННЫХ ИТЕРАЦИОННЫХ АЛГОРИТМОВ ДЛЯ РЕШЕНИЯ ЗАДАЧИ ФОРМИРОВАНИЯ ОПТИМАЛЬНЫХ ВАРИАНТОВ РАСПИСАНИЯ ВЫПОЛНЕНИЯ ЗАКАЗОВ
}

\author{
С. В. Грибков, О. Л. Седых
}

Национальный университет пищевых технологий

В статье предложена математическая модель многокритериальной задачи формирования производственных задач и оперативно-календарных планов по производству колбасных и мясных изделий. Разработаны усовершенствованные итерационные алгоритмы на основе алгоритма серых волков и алгоритма муравьиной колонии для решения задачи формирования оптимальных вариантов расписания выполнения заказов, что обеспечит при их применении проводить реконфигурации планов за короткое время.

Ключевые слова: математическая модель, планирование выполнения заказов, алгоритм муравьиной колонии, алгоритм серых волков. 